\title{
Iranian EFL Learners' Self-concepts and Beliefs as Language Learners
}

\author{
Mohammad Ali Heidari-Shahreza \\ Department of English, Faculty of Humanities, Shahreza Branch, Islamic Azad University, \\ Shahreza, Isfahan, Iran \\ E-mail address: maheidari.sh@gmail.com
}

\begin{abstract}
The present study expolred English as a foreign language (EFL) learners' self-concepts and beliefs as language learners. Through a mixed-methods research design and using descriptive statistics, 146 Iranian adult EFL learners were investigated on different dimensions of their self-concepts as language learners. In addition, their objectives as language learners were investigated to discern how their perceptions and beliefs could be related to the learning goals they aimed at. The findings revealed that the participants probably had some hindering feelings which negatively meddled with their linguistic performance. As a result, it might be the case that the inability of a learner to answer a question was not due to his/her lack of knowledge or inability to acquire the language but it was an aftermath of his/her feelings. Concerning the relation between EFL learners' beliefs and their learning objectives, the findings indicated that communicative, occupational and academic objectives for male participants and communicative, cultural and academic objectives for female participants were the three most important learning goals they had. Therefore, it seems quite reasonable to alter the teaching methods in a way that English students learn English in a more communicative, cooperative environment. Hence, the activities which are carried out in pairs or groups are preferable. Such learning environment may also serve as a solution to the learners' affective barriers and their perception of language class as a boring place.
\end{abstract}

Keywords: Iranian EFL learners; Learners' self-concepts and beliefs; Learning objectives; affective barriers

\section{INTRODUCTION}

Within the complex network of EFL learners' affective factors, learners' beliefs play a significant role in their ultimate success or failure as language learners (Abedini, Rahimi, \& Zare-ee, 2011). For instance, An EFL learner who views language as mainly a social activity, seeks to find (or create) opportunities to communicate with others in English over class time, whereas, another learner may be interested in reading foreign literature and hence, he or she may not enjoy the same class. Zeldin and Pajares (2000) indicate that learners do not typically participate in learning tasks for which they believe they are not skillful enough. Thus, their beliefs about their abilities influence "the choices they make, the effort they put forth, their inclinations to persist at certain tasks, and their resiliency in the face of failure." (Zeldin \& Pajares, 2000: 215). As Horwitz (1999) points out, research on learners' beliefs sheds light on how and why select various approaches to language learning. 
Despite numerous definitions, there is no consensus among second language acquisition (SLA) researchers on what needs to be labeled as beliefs. Victori and Lockhart (1995, p.224), for example, define learners' self-concepts and beliefs as "general assumptions that students hold about themselves as learners, about factors influencing learning and about the nature of language learning" (as cited in Bernat \& Lloyd, 2007, p. 81). Yang (1999) makes distinction between metacognitve and motivational beliefs. Metacognitive beliefs incorporate a) selfawareness or what they know about themselves; b) their attitude toward learning tasks; and c) their knowledge of learning strategies. Motivational beliefs also include factors such as learners' attitude about their ability, expectations and learning objectives. Nevertheless, it is generally assumed that learners' beliefs' incorporate their general assumptions and viewpoints they hold on various issues (see for example, Horwitz, 1987). In this regard, based on Horwitz's (1987) Beliefs About Language Learning Inventory (BALLI), quite a number of studies has been conducted on the link between learners' beliefs and factors such as proficiency level, culture gender and strategy use (Rieger, 2009).

A fundamental question is how EFL learners' self-concepts and beliefs are shaped. In this regard, various theoretical viewpoints are asserted about how beliefs come into existence. These frameworks have generally a cognitive (psychological) or socio-cultural origin. The researchers within a socio-cultural paradigm claim that beliefs are formed in a social context. The cognitive mainstream, however, vies self-concepts and beliefs as individual mental acts which cohere as networks of ideas in learners' mind (see Gabillon, 2007). There is also a mixed approach to learners' beliefs which relies on both a socio-cultural and cognitive approach. This so-called socio-cognitive approach holds a mediate position by considering beliefs and concepts as a joint product of individuals' cognition and the social milieu in which such psychological states are formed.

\section{METHODOLOGY}

This study based on Heidari-Shahreza's study (2014) explored a sample of Iranian EFL learners' self-concepts and beliefs as EFL learners through a mixed-methods research design and using descriptive statistics. Using a survey as the data collection tool, the participants were investigated on different dimensions of what they regard themselves as language learners. In addition, as a part of the survey, their goals and objectives as language learners were investigated to discern how their self-concepts and beliefs could be related to the learning goals they aimed at. The present study is a part of a larger research project which in addition to learners' self-concepts, investigated their beliefs about their English teachers. Two research questions guided the study:

1. What are EFL learners' self-concepts and beliefs as language learners?

2. How are these self-concepts and beliefs related to their learning objectives?

\section{1. Participants}

The participants of the study were 146 EFL learners at an Iranian language institute (see Table 1). They included 68 males and 78 females. They were all young adult learners and had almost at the same age (average age $=21.5$ ). Prior to the study, to select the final participants, English records of 293 students in University Entrance Examination (UEE) were taken into account and those students who could achieve a mid-band score of 45-65 were identified. Afterward, using Oxford Placement Test (OPT), their current level of language proficiency 
was determined. Following this test, those learners who had fallen into the category of 'intermediate' were labeled as final participants.

Table 1. Participants of the study.

\begin{tabular}{cccc}
\hline Total Number & Age & OPT level & UEE score \\
\hline 146 & 21.5 & intermediate & $45-65$ \\
First language & Foreign language & Gender & Occupation \\
Persian & English & $68 \mathrm{~m}, 78 \mathrm{f}$ & student \\
\hline
\end{tabular}

\section{2. Material \& Instruments}

To gain insight into the participants' self-concepts and beliefs as language learners, the researcher composed a survey. Using a survey seemed appropriate because as Mackay and Gass (2005) points out: "The survey, typically in the form of a questionnaire, is one of the most common methods of collecting data on attitudes and opinions....Questionnaires allow the researchers to gather information that learners are able to report about themselves, such as their beliefs and motivations about learning or their reactions to learning and instruction and activities- information that is typically not available production data alone."

The survey included a part on EFL learners' participants in which the participants were asked to identify their learning goals as language learners based on five general themes of a) occupational; b) communicative; c) academic; d) cultural and e) recreational. The second part of the survey, focused on the primary purpose of the study which was EFL learners' selfconcepts and beliefs as language learners. This part contained seven general themes which probed various aspects of learner-teacher interaction and learners' attitudes and perceptions.

\section{3. Procedure}

First of all, the participants were sufficiently informed of the scope of research. It was clarified that their participation in the study was voluntary and a decision to leave the study would not result in any penalty or would not affect their relationship with their teachers at the institute. After this oral consent, the survey sheets were distributed among the participants during their regular class time. There was no time limit. Nevertheless, it took about 20 minutes for the participants to hand in the sheets.

\section{4. Data Analysis}

After collecting the participants' answers through the survey, the researcher analyzed the collected data based on a number of qualitative themes to draw significant patterns of the learners' perceptions and beliefs. As for the second part of the survey, the participants' answers were first categorized based on three scales of agreement, undecidedness and disagreement and, then, further analysis was exercised. Moreover, the data was also scrutinized based on the participants' gender. To simplify the interpretation of the data, descriptive statistics were also used. 


\section{RESULTS}

\section{1. Part One: EFL Learners' Learning Objectives}

As Figure 1 indicates, communicative objective (89.5\%) is the most important learning goal for the participants. This objective is followed by cultural, occupational, academic and recreational objectives respectively $(75.5 \%, 71.5 \%, 64 \%$ and $29.5 \%)$.

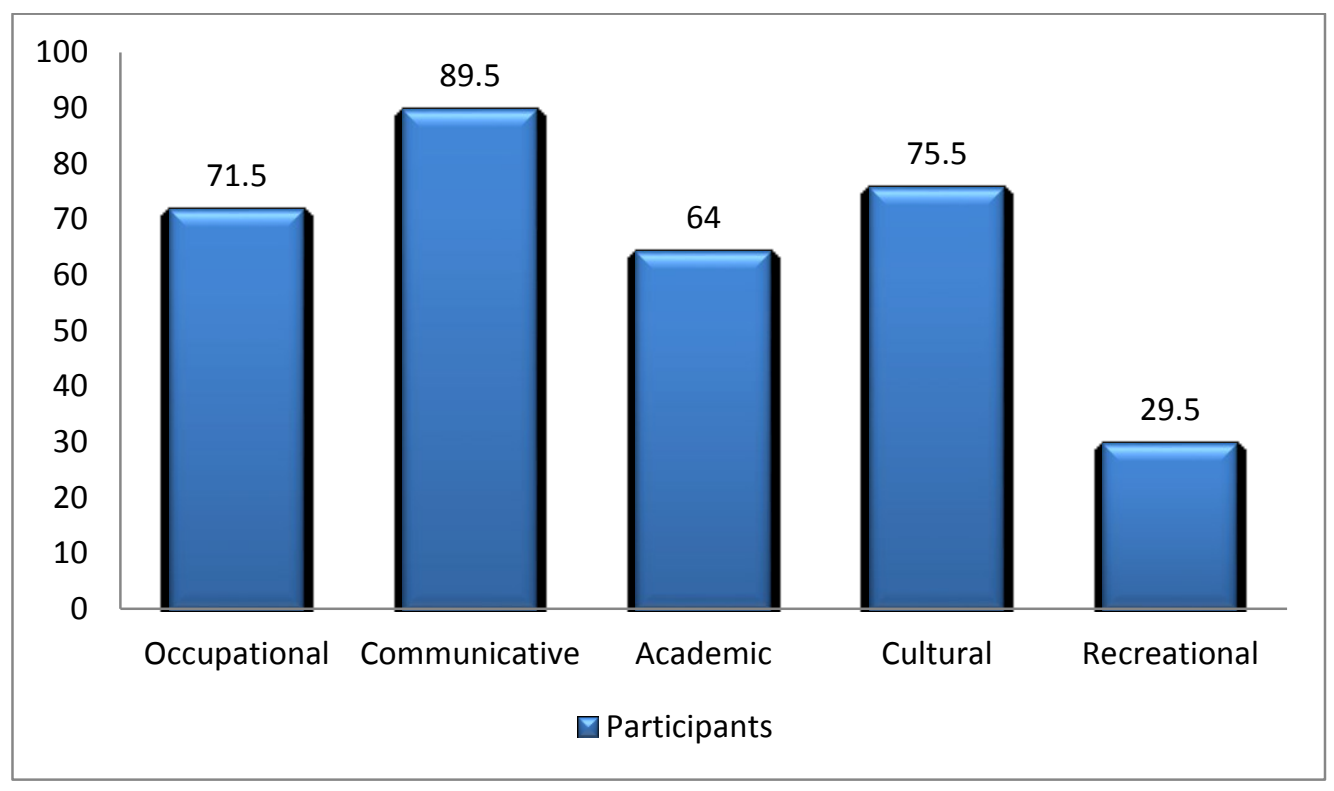

Figure1. EFL learners' learning objectives

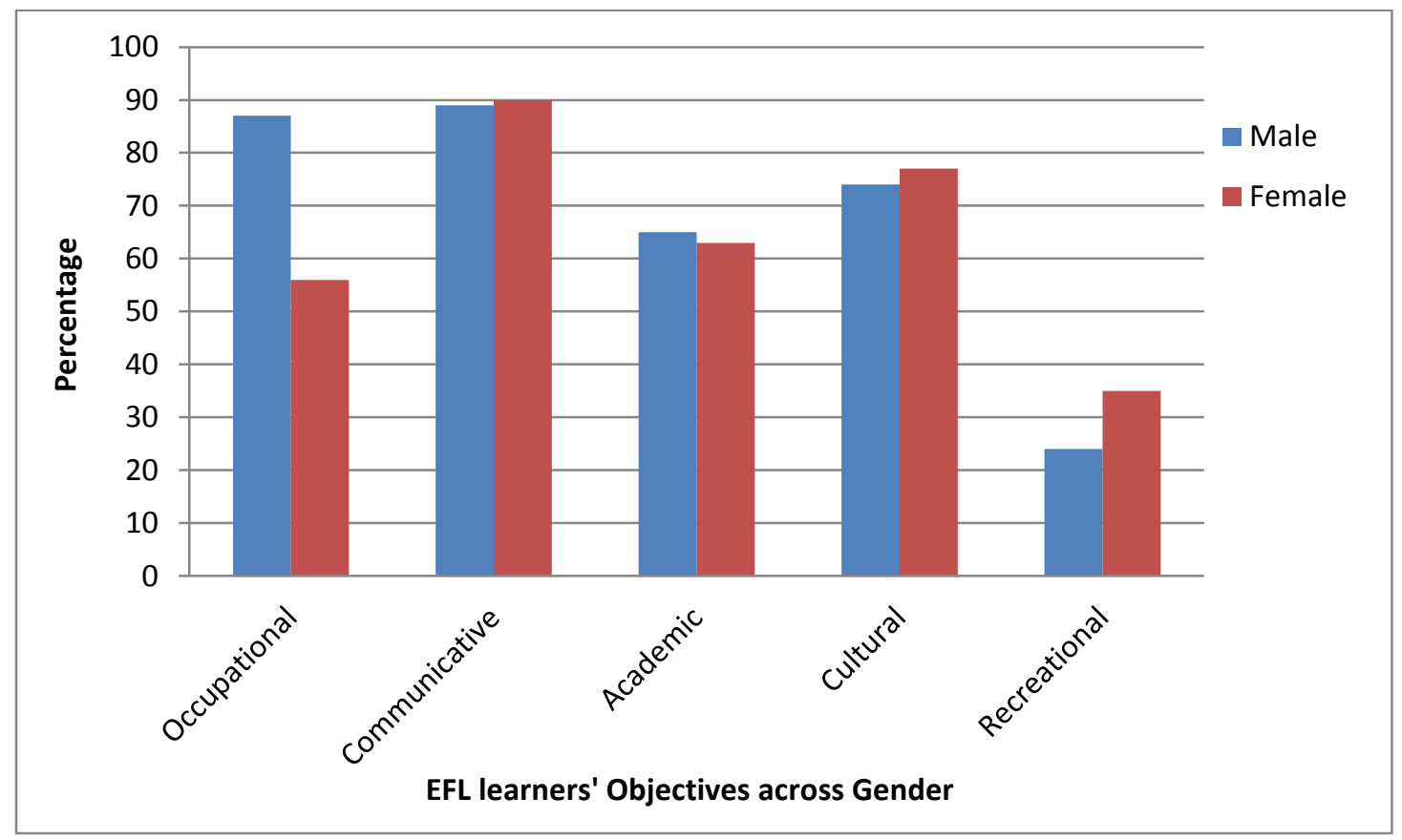

Figure 2. EFL learners' learning objectives across gender. 
The researcher was also interested to know whether or not the observed pattern of objectives held true across gender. Thus, the data was also analyzed with respect to two groups of male and female partcipants. As Figure 2 shows, gender does not seem a decisve factor for communicative, academic, cultural and recreational objectives. For the occupatonal objective, however, it seems male participants tended to be more interested ( $87 \%$ males vs. $56 \%$ females).

\section{2. Part 2: EFL Learners' Self-concepts and Beliefs as Language Learners}

The analysis of the second part of the survey revealed that a significant number of the participants were probably involved in some affective barriers. In simple terms, they seem to have some hindering feelings which negatively meddle with their true language ability and achievements. As Table 2 indicates, the majority of the participants (about $80 \%$ ) do not ask their teachers for clarification when a point is not clear to them. What is more, they do not usually volunteer to answer questions. It is also interpreted from the analysis that almost half of the subjects a) feel disappointed when their answers are wrong b) do not participate the activities because they fear of being ridiculed or rejected by others c) get embarrassed when they are called on by teacher d) know the answer, However, are unable to articulate it clearly. It is also worth noting that only $32 \%$ of the subjects would like to learn individually.

Table 2. EFL learners' self-concepts and beliefs as language learners.

\begin{tabular}{|c|c|c|c|c|}
\hline Item & Affective themes & Agreement & Undecidedness & Disagreement \\
\hline 1 & Not asking for clarification & 80 & 13 & 7 \\
\hline 2 & $\begin{array}{c}\text { Not volunteer to answer } \\
\text { questions }\end{array}$ & 79 & 6 & 15 \\
\hline 3 & $\begin{array}{c}\text { Disappointed with wrong } \\
\text { answer }\end{array}$ & 60 & 21 & 19 \\
\hline 4 & Reluctant to participation & 44 & 20 & 36 \\
\hline 5 & Embarrassed when called on & 40 & 28 & 32 \\
\hline 6 & Unwilling to learn in groups & 68 & 9 & 17 \\
\hline 7 & Unable to articulate clearly & 60 & 15 & 25 \\
\hline
\end{tabular}

After having looked into the participants' learning objectives, the data was analyzed to see what, based on such observed incentives, the participants perceived of themselves as language learners. As shown in Table 2, the participants' self-concepts and beliefs as language learners are not positive especially for items one, two, three, six and seven. For these themes more than half of the participants felt an affective barrier $(80 \%, 79 \%, 60 \%, 68 \%$ and $60 \%$ respectively). Notably, Heidari-Shahreza (2014), investigating a number of affective themes in relation to language teachers with the same sample of participants, report that "the participants' perceptions and beliefs about their teachers' teaching skills and strategies are not positive". In addition, a significant number of his participants felt that their learning environment was boring $(87 \%)$. In other words, in their opinion, their teachers failed to create an interesting learning atmosphere. 


\section{DISCUSSION \& CONCLUSIONS}

The first research question was concerned with EFL learners' self-concepts and beliefs as language learners. The findings revealed that the participants probably had some hindering feelings which negatively meddle with their linguistic performance. As a result, it might be the case that the inability of a learner to answer a display question is not due to his lack of knowledge or inability to acquire the language but it is an aftermath of his/her feelings (see also Abedini, Rahimi, \& Zare-ee, 2011).

Concerning the affective themes, the participants had notable affective concerns. That is, most of the participants did not ask their teachers for clarification when a point was not clear to them. What is more, they did not usually volunteer to answer questions. The findings implied that almost half of the subjects felt disappointed when their answers were wrong; and did not participate in the activities because they feared of being ridiculed or rejected by others; got embarrassed when they were called on by teacher and knew the answer, However, they were unable to articulate it clearly. Furthermore, they notably felt that their learning atmosphere (i.e. language class) was boring. While the characteristics of language classrooms are dependent on various factors that only part of which pertain to language teachers, it seems EFL teachers need to pay attention to how learners perceive and interact with their learning environment (Abdolahzadeh \& RajaeeNia, 2014).

Therefore, it seems quite reasonable to alter the teaching methods in a way that English students learn English in a more communicative cooperative environment. Hence, the activities which are carried out in pairs or groups are preferable. Surveys, as used in the present study, are also helpful in this regard to find a way to EFL learners' realm of self-concepts and beliefs (see Pan \& Block, 2011). EFL teachers can run such surveys (either in oral or written format) on a regular basis to trace their learners' perception of the teaching and learning tasks.

Concerning the relation between EFL learners' beliefs and their learning objectives, the findings indicated that communicative, occupational and academic objectives for male participants and communicative, cultural and academic objectives for female participants were the three most important learning goals. As for the first objective (i.e. communicative), it is recommended that EFL teachers direct their focus of teaching to more communicative language teaching approaches. This way, in addition to fulfilling their learners' primary objective, teachers are better able to create an interesting, diverse atmosphere in language classrooms. Such learning environment may also serve as a solution to the learners' lack of motivation and their perception of language class as a boring place (Csizér \& Dörnyei, 2005).

The second common objective among male and female EFL learners in this study was academic learning goal. This priority may come from the fact that the participants were students themselves and needed English as a (university) student regularly. In this regard, it is recommended that EFL teachers expand their teaching scope to encompass their academic needs. English for academic (EAP) purposes can also be implemented for those learners who feel urgent academic needs (see Neumann \& McDonough, 2014).

As any piece of research, this study was also limited in some ways. Firstly, the participants of the study came from only one language institute; interested researchers may follow the same line of research by incorporating a larger sample of participants from a more representative number of institutes. Secondly, other levels of language proficiency and age groups may be used to compare and contrast to what extent the observed results repeat themselves. Finally, using interview as a data collection tool may be a helpful complement to gain more insights into EFL learners' self-concepts and beliefs. 


\section{References}

[1] Abdolahzadeh E., Rajaee Nia M., Procedia - Social and Behavioral Sciences 98 (2014) 22- 28

[2] Abedini A., Rahimi A., Zare-ee A., Procedia - Social and Behavioral Sciences 28 (2011) 1029-1033

[3] Bernat E., Llyoyd M., Australian Journal of Educational and Developmental Psychology 7 (2007) 79-91

[4] Csizér K., Dörnyei Z. The Modern Language Journal 89 (2005) 19-36.

[5] Horwitz E. K. (1987). Surveying student beliefs about language learning. In Rubin, Joan \& Wenden Anita (Ed). Learner strategies in language learning (pp.119-129). London: Prentice Hall.

[6] Horwitz E. K., System, 27 (1999) 557-576.

[7] Mackey A., Gass S. M. (2005). Second language research: Methodology and design. Mahwah, NJ: Lawrence Erlbaum Associates.

[8] Neumann H., McDonough K., Journal of English for Academic Purposes 15 (2014) 14-26.

[9] Pan L., Block D., System 39 (2011) 391-402.

[10] Rieger B. (2009). Exploring gender and target language effect on Hungarian EFL learners' beliefs about languagelearning. In R. Lugossy, J. Horváth, \& M. Nikolov (Eds.), UPRT 2008: Empirical studies in English applied linguistics (pp. 29-42). Pécs: Lingua Franca Csoport

[11] Victori M., Lockhart W., System 23 (1995) 223-234.

[12] Yang N. D., System 27 (1999) 515-535.

[13] Zeldin A. L., Pajares F., American Educational Research Journal 37 (2000) 215-246.

[14] Hussein Meihami, Bahram Meihami, International Letters of Social and Humanistic Sciences 2 (2014) 10-19.

[15] Hussein Meihami, Bahram Meihami, International Letters of Social and Humanistic Sciences 5 (2014) 63-72.

[16] Mohammad Ali Heidari-Shahreza, International Letters of Social and Humanistic Sciences 20 (2014) 14-21.

[17] Hamedreza Kohzadi, Fatemeh Azizmohammadi, Fatemeh Samadi, International Letters of Social and Humanistic Sciences 22 (2014) 50-62.

[18] Mohammad Ali Heidari-Shahreza, International Letters of Social and Humanistic Sciences 25 (2014) 25-33. 


\section{Appendix 1: The survey}

Here is a survey designed to evaluate your learning preferences, feelings and the kind of teacher you like as the students of English. Please follow the instructions carefully and respond to the items sincerely. Your cooperation is greatly appreciated.

\section{Part One}

Read each item carefully. Circle 'Yes' if the objective mentioned is of primary importance to you and 'No' if it is of no or secondary importance.

I would like to learn English...

a) to promote in my profession(or to find a better job) $\quad$ Yes $\quad$ No

b) to be able to communicate with English speakers. Yes No

c) to succeed in academic courses requiring English proficiency. Yes No

d) to expand my knowledge of English language and culture. $\quad$ Yes No

e) to amuse myself (just as a hobby or pleasurable activity.) Yes No

\section{Part Two}

Read each item carefully. Circle 'agree', not sure' or 'disagree'.

In class, I, as a learner of English,

A. often do not ask my teacher for clarification when a point is not clear to me.

Agree/not sure/disagree

B. do not usually volunteer to answer when a question is raised.

Agree/not sure/disagree

C. often feel disappointed when my answer is wrong.

Agree/not sure/disagree

D. do not usually take part in activities (e.g. discussions) because I fear of being ridiculed or rejected by others.

Agree/not sure/disagree

E. get embarrassed whenever the teacher calls on me to answer a question.

Agree/not sure/disagree

F. do not like cooperation with other learners. I like to learn individually.

Agree/not sure/disagree 
G. most often know the answer. However, I usually fail to articulate it clearly. Subsequently, my answer is regarded wrong by teacher.

Agree/not sure/disagree 